\title{
Anthropogenic climate change shown by local wave conditions in the North Sea
}

\author{
Arnt Pfizenmayer*, Hans von Storch \\ Institute of Coastal Research, GKSS Research Centre, 21502 Geesthacht, Germany
}

\begin{abstract}
In the central North Sea we have observed an increase in the frequency of eastwardly propagating waves in the last 4 decades. To assess the significance of this change, wave statistics for the 20th century were reconstructed with a statistical model. With a linear multivariate technique (redundancy analysis), monthly mean air pressure fields over the North Atlantic and Western Europe were downscaled on the intramonthly frequency of directional wave propagation. When compared against this reference, the recent change appears statistically significant at the $5 \%$ level. In order to investigate the reason for this local climatic change, the reconstruction was compared with the downscaled results of control and transient GCM scenarios (ECHAM4-OPYC3) and with the results obtained in a high-resolution time-slice experiment with increased concentrations of greenhouse gases and aerosols. Both estimates are qualitatively consistent with the changes observed in the last 4 decades. We suggest that the recent increase in eastward propagation is a local manifestation of anthropogenic global climate change.
\end{abstract}

KEY WORDS: Climate change $\cdot$ Detection $\cdot$ Attribution $\cdot$ Wave climate $\cdot$ Statistical downscaling

\section{INTRODUCTION}

All current climate models predict anthropogenically induced climate change due to an increasing concentration of greenhouse gases in the atmosphere. According to many studies (e.g. Mitchell \& Daley 1995, Hegerl et al. 1996, Stott \& Tett 1998, Wigley et al. 1998, Zwiers 1999), some of the observed climate trends over the last few decades are unlikely to have been caused by natural variability, but are roughly consistent with the model predictions for the anthropogenic effect. These studies make use of large-scale characteristics of the state of the atmosphere and employ different techniques, such as optimal fingerprints (Hegerl et al. 1996), to reduce the spatial climate change signal to a single detection variable (for an overview, see Zwiers 1999). Stott \& Tett (1998) used a time-dependent definition of the detection variable; Leroy (1999) used not only horizontal information, but also vertical temperature profiles. A common feature of these detection

*E-mail: arnt.pfizenmayer@gkss.de studies is that they operate with large-scale features, because of the view that general circulation models (GCMs) cannot be trusted at smaller scales (von Storch 1995). Studies of the possible limits of detection indicate that climate change can only be detected at spatial scales greater than $2000 \mathrm{~km}$ (Stott \& Tett 1998). In this study we demonstrate that this limit may be circumvented by applying downscaling techniques.

Several papers have dealt with the evolution of the wave climate in the North Atlantic and the North Sea (Kushnir et al. 1997, Günther et al. 1998, WASA Group 1998, Grevemeyer et al. 2000). They document an increase in mean wave heights and extreme values in the last few decades for this area by examining observations or results from wave models or indirect measurements, such as the microseismic activity in the coastal area. We analyse the 'observed' record of the monthly frequency of directional propagation of the wave field near the Ekofisk oil field in the North Sea (Fig. 1), to investigate recent and future development. Actually, we are not dealing with in situ observations, but with 'analysed' data, derived from the output of an operationally used and successfully validated wave 


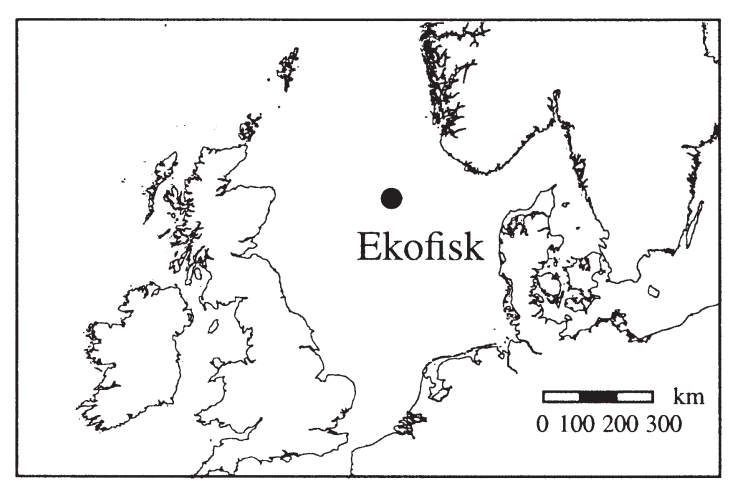

Fig. 1. Study area, $56^{\circ} \mathrm{N}, 3^{\circ} \mathrm{E}$ in the North Sea, near Ekofisk

model (Komen et al. 1994), forced with observed wind fields from the period 1955-94 (Günther et al. 1998).

To detect anthropogenic climate change, reliable estimates of the range of naturally occurring variations are needed. Data from the past 4 decades are insufficient for this purpose. In order to obtain a longer period, we use a statistical downscaling model (von Storch 1995) to reconstruct the aspects of the wave climate in the 20th century. The downscaling model uses the gridded observed monthly sea level pressure (SLP) over the North Atlantic and Western Europe as the predictor, while the monthly frequencies of eastwardly and westwardly propagating waves are used as the predictand. This link is based on the assumption that the large-scale circulation patterns, such as the Arctic Oscillation (AO) pattern or the North Atlantic Oscillation (NAO; Hurrell 1995), determine, to a large extent, the changing statistics. The frequency in the eastwardly propagating waves is also partly correlated with the NAO. For example, a more intense NAO is connected with more storminess over the North Atlantic, so we get more westerly winds and more eastward waves (Kushnir et al. 1997). Because of the probable sensitivity of the AO to greenhouse-gas forcing (Fyfe et al. 1999, Shindell et al. 1999), we also expected an influence on the wave climate in the North Sea.

Many statistical downscaling techniques have been proposed to derive local-scale information from largescale information. A comparison of the major methods can be found in Wilby \& Wigley (1997), Wilby et al. (1998) or Zorita \& von Storch (1999). In our case we used a multivariate linear statistical model called redundancy analysis (RDA; von Storch \& Zwiers 1999). With the long available time series (1900-96) for SLP, we were able to reconstruct wave propagation for most of the 20th century. This derived record provided us with a better estimate of the range of natural variability, unrelated to anthropogenic climate change.

For climate change detection we used a low-pass filter with a climate-relevant time scale (30 yr), so that the interannual and interdecadal natural variability is suppressed. We adopt a critical value of $5 \%$ for rejecting the null hypothesis that recent climate variability is not within the limits of historic variability.

With the recent trend we found in the directional propagation of waves at Ekofisk, the question arises as to whether this significant local change in the wave climate is attributable to anthropogenic causes. To address this question, we compared the 20th century reconstruction with downscaling results obtained from the SLP fields simulated in a GCM (ECHAM4) under increasing greenhouse-gas concentrations and an equivalent control run. Prior to this comparison, we found the statistical relationship under a climate change condition to be stable in an independent wave data set. Here we used a 240 yr transient run, a 300 yr control run and 1 high-resolution time-slice experiment over a 30 yr period. For significance testing, different confidence intervals were calculated.

The paper is divided into 7 sections. The description of the data is contained in Section 2. RDA is introduced in Section 3. The analysis of the wave climate in the 20th century is performed in Section 4. In Section 5 the statistical model is applied to derive the climate change scenarios. The detection strategy and the results are presented in Section 6. Section 7 is the conclusion.

\section{DATA DESCRIPTION}

For the purpose of this study, only the winter half year (ONDJFM), which has a significant wave climate, is used.

2.1. Wave data. A problem with using in situ observed wave data is the unknown degree of inhomogeneity. Observation techniques changed in the 1980s from visual assessment to the use of increasingly accurate instruments. In the WASA Project (WASA Group 1998) a data set was produced describing the variation of the wave field for $40 \mathrm{yr}$ with the dynamical wave model WAM and forced with a high-resolution, 6-hourly $10 \mathrm{~m}$ wind derived from air pressure analyses by the Norwegian Weather Service (DNMI). The model has a resolution of $1.5^{\circ} \times 1.5^{\circ}$ for the whole North Atlantic from 9.5 to $80^{\circ} \mathrm{N}$ and from $78^{\circ} \mathrm{W}$ to $48^{\circ} \mathrm{E}$ and a nested fine grid in the Northeast Atlantic (38 to $77^{\circ} \mathrm{N}$, $30^{\circ} \mathrm{W}$ to $45^{\circ} \mathrm{E}$ ). Two equivalent data sets were produced by the DNMI, one forced with the wind fields of a control scenario and the other with wind fields from a doubled $\mathrm{CO}_{2}$ time-slice experiment (T106, see below).

WAM is a third generation wave model which solves the wave transport equation explicitly without any presumption of the shape of the wave spectrum. In addition to a number of consistency checks and quality 
controls of the product runs, the model results were successfully compared with measurements at several locations (Günther et al. 1998). A detailed description of this wave model can be found in Komen et al. (1994)

We used the significant wave heights and propagating direction at a single grid point of the WASA data set. The location was $56^{\circ} \mathrm{N}, 3^{\circ} \mathrm{E}$, in the central North Sea near Ekofisk (Fig. 1), the size of the grid box was $0.7^{\circ}$ longitude $\times 0.5^{\circ}$ latitude, the time step was $3 \mathrm{~h}$ and the period covered was 1955-94. For the time-slice experiments the time step was $6 \mathrm{~h}$, and each experiment covered a period of $30 \mathrm{yr}$.

2.2. Sea level pressure data. To fit the statistical model in order to reconstruct the wave climate of the 20th century, we used the monthly mean SLP from an analysis of observations from the National Center for Atmospheric Research (NCAR). This data set is mostly homogeneous and has a resolution of $5^{\circ} \times 5^{\circ}$. The qualitative problems of the NCAR data (Williams \& van Loon 1976, Kevin \& Paolino 1980), especially at the beginning of the 20th century and during World War II, are only marginally relevant in this study, because we only used the large-scale monthly mean circulation pattern from the SLP, local errors being thus irrelevant. The area we used covered the North Atlantic and Western Europe (30 to $70^{\circ} \mathrm{N}, 60^{\circ} \mathrm{W}$ to $20^{\circ} \mathrm{E}$ ).

2.3. Climate scenario and control run. For the estimation of future changes in the wave climate due to an increased concentration of atmospheric greenhouse gases, we used one transient run, with a continuously increasing greenhouse-gas concentration, and a control run. Both runs were performed with a regular coupled atmosphere-ocean model. Additionally we obtained output from 2 'atmosphere-only' time-slice experiments with a high-resolution model at our disposal.

For the transient climate scenario and the control run we used the output of a long integration with the atmosphere-ocean coupled model ECHAM4-OPYC3. The horizontal resolution of the ECHAM4 atmosphere spectral model is about $2.8^{\circ} \times 2.8^{\circ}(\mathrm{T} 42)$; it uses 19 atmospheric levels, with the last one located at $10 \mathrm{mb}$. The control run covered a period of $300 \mathrm{yr}$ and was forced with a historical greenhouse-gas concentration from 1990. The transient run spanned from 1860-2099, with observed greenhouse-gas concentrations until 1990, after which an increase of about $1 \% \mathrm{yr}^{-1}$ was imposed (IS92a scenario, IPCC [Intergovernmental Panel on Climate Change] 1996). For the northern hemisphere the model produces under present-day conditions a realistic mean surface circulation and its most important pattern of variability (Zorita \& Gonzales-Rouco 2000). Technical details can be found in Roeckner et al. (1998).

The high-resolution time-slice experiment (T106, $1.1^{\circ} \times 1.1^{\circ}$ horizontal resolution, ECHAM4) is a collab- oration between the Max Planck Institute for Meteorology in Hamburg (MPI) and the Danish Meteorological Institute (DMI). These simulations (control [1968-97] and $2 \times \mathrm{CO}_{2}$ [2060-99]) each covered a period of $30 \mathrm{yr}$. The experimental design of these simulations is described in May (1999).

\section{REDUNDANCY ANALYSIS OF THE LINK BETWEEN THE FREQUENCY OF EASTWARDLY PROPAGATING WAVES AND THE ATMOSPHERIC CIRCULATION}

Our downscaling concept is based on the assumption that monthly statistics of wave characteristics are linearly conditioned by the monthly atmospheric state. We determined this link with a multivariate technique, namely redundancy analysis (RDA; Tyler 1982). RDA determines coupled pairs of patterns in 2 different fields so that a regression from the predictor field (SLP) on the predictand field (wave statistics) is optimal in representing variance of the predictand. Details about RDA can be found in von Storch \& Zwiers (1999), and an application in Langenberg et al. (1999).

As a predictor for the wave climate, we chose the monthly mean SLP field. With the monthly mean field, all the details of the baroclinic variability responsible for the generation of waves are averaged out. However, the statistics of the baroclinic variability is engraved in the mean field, as there is a strong link between anomalies of the mean field and of the standard deviation of the band-pass-filtered variability (Zorita et al. 1992). The same predictor has been used successfully in a series of other downscaling studies dealing with storm surge statistics and wave heights (WASA 1998, Langenberg et al. 1999).

A problem may arise if the waves in the North Sea are relatively old, originating from remote areas. However, this is not the case in the North Sea; Bauer et al. (2000) examined the history and the memory of wind forcing for waves in the North Sea. Waves in the North Sea are on average $1 / 2 \mathrm{~d}$ old, indicating a short wind duration and a short fetch for the evolving waves. Only individual extreme events originating in the NE Atlantic and coming through the North Sea are around 2 to $3 \mathrm{~d}$ old. Consequently we assumed that monthly wave statistics can generally be related without a time lag to the monthly SLP.

\subsection{Redundancy analysis}

A linear regression model was built which relates 2 sets of random vectors, $\boldsymbol{S}_{t}$ and $\boldsymbol{Q}_{t}$. The vector time 

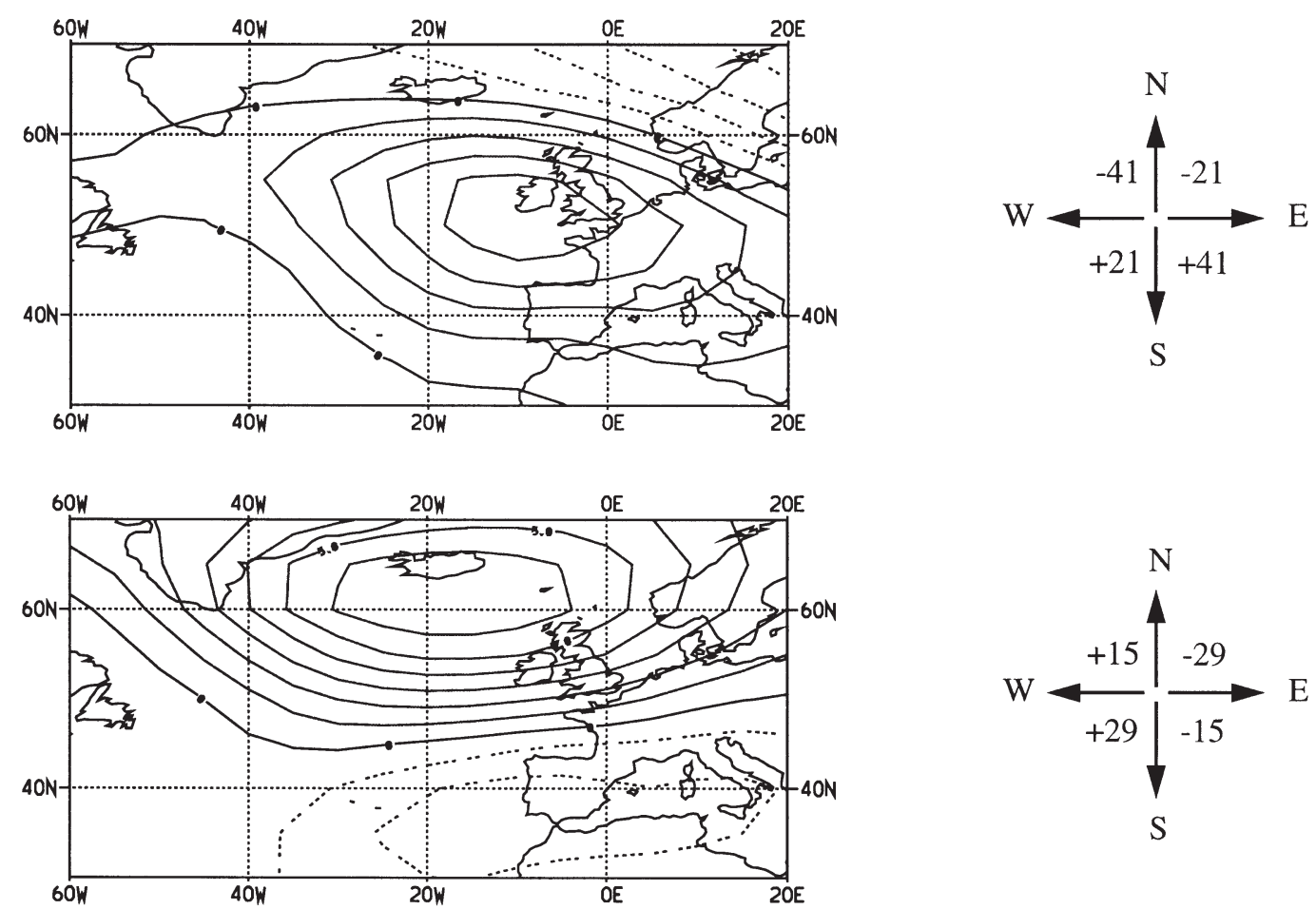

Fig. 2. The 2 pairs of redundancy patterns of observed winter (ONDJFM, 1955-64) sea-level pressure (SLP; hPa) in the North Atlantic sector (left) and the 3-hourly frequency of monthly wave direction (right). Top (first pair): correlation between the time coefficients is 0.87 . Pattern for the wave frequency explains $67 \%$ of the variance. Bottom (second pair): correlation between the time coefficients is 0.79 . Pattern for the wave frequency explains $33 \%$ of the variance

series $\boldsymbol{S}_{t}$ represents the anomalies of the winter half year (ONDJFM) monthly mean SLP distribution. $\boldsymbol{Q}_{t}$ represents the anomalies of the meridional $(m)$ and zonal $(z)$ frequency of the monthly wave propagation direction.

$$
\boldsymbol{Q}_{t}=\left(\begin{array}{c}
m \\
z
\end{array}\right)
$$

For SLP we used 5 empirical orthogonal functions (EOFs) (von Storch \& Zwiers 1999) for data compression prior to the analysis.

The result of the RDA is pairs of vectors $\left(\boldsymbol{p}^{s_{i} k}, \boldsymbol{p}^{q_{i} k}\right)$ and time coefficients $\alpha_{s_{i} k}(t)$ and $\alpha_{q_{i k}}(t)$ :

$$
\begin{aligned}
\boldsymbol{S}_{t} & =\sum_{k=1}^{K} \alpha_{s ; k}(t) \boldsymbol{p}^{s_{i} k} \\
\boldsymbol{Q}_{t} & =\sum_{k=1}^{K} \alpha_{q_{; k}}(t) \boldsymbol{p}^{q_{;} k}
\end{aligned}
$$

so that the regression of $\boldsymbol{p}^{s_{i} k}$ and $\boldsymbol{p}^{q_{i} k}$ describes the maximum variance of $\boldsymbol{Q}$ for a chosen number $K$.

$$
\hat{\boldsymbol{Q}}_{t}=\sum_{k=1}^{K} \rho_{k} \alpha_{s ; k}(t) \boldsymbol{p}^{s ; k}
$$

The predictor patterns $\boldsymbol{p}^{s_{i} k}$ are orthonormal, whereas the patterns $\boldsymbol{q}^{q_{i} k}$ are linearly independent. The first pattern pair is chosen so that a maximum of the vari- ance in $\boldsymbol{Q}$ is explained. The second pair is chosen so that a maximum of the additional variance is represented. The coefficients are obtained by the projections:

$$
\begin{gathered}
\alpha_{s ; k}=\boldsymbol{S}^{T} \boldsymbol{p} \boldsymbol{A}^{s_{;} k} \\
\alpha_{q ; k}=\boldsymbol{S}^{T} \boldsymbol{p}^{q ; k}
\end{gathered}
$$

where $\boldsymbol{p} \boldsymbol{A}^{s_{i} k}$ are the adjoints to the patterns $\boldsymbol{p}^{s_{i} k}$.

The coefficients are normalized to 1 :

$$
\operatorname{Var}\left(\alpha_{q ; k}\right)=\operatorname{Var}\left(\alpha_{s ; k}\right)=1
$$

so that the components of $\boldsymbol{p}^{q_{i} k}$ can be interpreted as anomalies which belong to $\boldsymbol{p}^{s_{i} k}$.

The regression model $\alpha^{q_{i} k}=\rho_{k} \alpha_{s ; k}$ for the RDA coefficients $\alpha_{s_{i} k}$ and $\alpha_{q ; k}$ is a downscaling model which relates the large-scale air pressure state to the intramonthly frequency of wave direction. A reconstruction in 2-dimensional space, here the 2 possible wave directions, is obtained using:

$$
\boldsymbol{Q}_{t}=\left(\begin{array}{c}
m \\
z
\end{array}\right)=\sum_{k=1}^{K} \rho_{k} \alpha_{s ; k}(t) \boldsymbol{p}^{s_{i} k}
$$

With the regression model Eq. (7), we can estimate the probability of the wave direction for given anomalies of observed or simulated air pressure fields, 
$S=\sum \alpha_{s ; k} \boldsymbol{p}^{s_{i k}}$. The downscaling model uses both RDA pairs, so $K=2$ in Eq. (3).

The RDA was fitted with data from 1955-64. The first RDA pair (Fig. 2, top) describes two-thirds of the explained variance of the frequency of wave direction. The time coefficients from the SLP and wave direction are correlated at 0.87 . The SLP pattern is characterized by a low-pressure system over Scandinavia and a highpressure system west of Ireland. The associated pattern for the wave direction shows an increase in the frequency in an eastward direction and a smaller increase in the southward direction. When such an anomalous SLP pattern prevails, more low-pressure systems pass Scandinavia in a southeastward direction. Consequently more northwesterly winds occurred at Ekofisk behind the front of cyclones over the North Sea.

The second RDA pattern pair (Fig. 2, bottom) is correlated at 0.79 and exhibits a small decrease in the eastward direction and an increase in the southward direction for the wave probability. In this case the SLP pattern is dominated by a high-pressure system over the North Atlantic. On the east side of the anticyclone there is a northeasterly air flow over the North Sea. In the opposite case the anomalous southwesterly winds are superposed on the mean wind fields, so that more waves propagate more often than normal in a northeasterly direction.

\subsection{Validation}

The model was validated in an independent period (1965-94) by comparing 'observed' intramonthly frequencies of wave directions with estimated values. In Fig. 3 the solid line is the 'observations', the dashed line is the modelled time series and the grey area is the fitting period (1955-64). We used 2 conventional measures of skill for the comparison: the correlation skill score $\rho_{K}$ (Eq. 8) and the percentage of represented variance $\varepsilon_{K}$ (Eq. 9) for $k=m, z$ (Livezey 1995),

$$
\begin{aligned}
\rho_{K} & =\frac{\operatorname{Cov}\left(\hat{\boldsymbol{q}}_{k ; t}, \boldsymbol{q}_{k ; t}\right)}{\sqrt{\operatorname{Var}\left(\hat{\boldsymbol{q}}_{k ; t}\right) \operatorname{Var}\left(\boldsymbol{q}_{k ; t}\right)}} \\
\varepsilon_{K} & =1-\frac{\operatorname{Var}\left(\hat{\boldsymbol{q}}_{k ; t}-\boldsymbol{q}_{k ; t}\right)}{\operatorname{Var}\left(\boldsymbol{q}_{k ; t}\right)}
\end{aligned}
$$

where $\hat{\boldsymbol{q}}_{k_{i} t}$ is the estimated $k$ th wave direction coefficient in the month $t$.

For the eastward direction the correlation is 0.8 and the explained variance $50 \%$; for the southward direction the respective values are 0.78 and $48 \%$. The good agreement demonstrates that the mean atmospheric pressure state is a good indicator for this part of the wave climate.

\section{ANALYSIS OF THE PAST WAVE CLIMATE}

For the reconstruction of the 20th century and for the climate experiments we used the whole period of available wave data (1955-94). The patterns and their links proved to be effectively unchanged. Before applying the downscaling model to reconstruct the wave climate, we analysed trends in the 1955-94 wave simulations with the WAM model. Trends of (1) the 90th percentiles (the 90th percentile is the value which is greater than $90 \%$ of the values and smaller than the other $10 \%$ ) of intramonthly significant wave heights, (2) the 90th percentiles of intramonthly significant wave heights separated by direction, and (3) the intramonthly frequencies of eastward wave propagation were all considered. All trends were normalized with the standard deviation of the respective variable, so that they were dimensionless, representing the $40 \mathrm{yr}$ change divided by the month-to-month standard deviation.

We found a positive trend for the 90th percentile of intramonthly significant wave heights in the Central North Sea during the winter half year $(0.39 \times$ standard deviation, $0.45 \mathrm{~m})$. Similar results were obtained by Günther et al. (1997), Kushnir et al. (1997), the WASA Group (1998) and Grevemeyer et al. (2000). If the wave direction is taken into account, this increase is mostly due to the zonally propagating waves: their trend

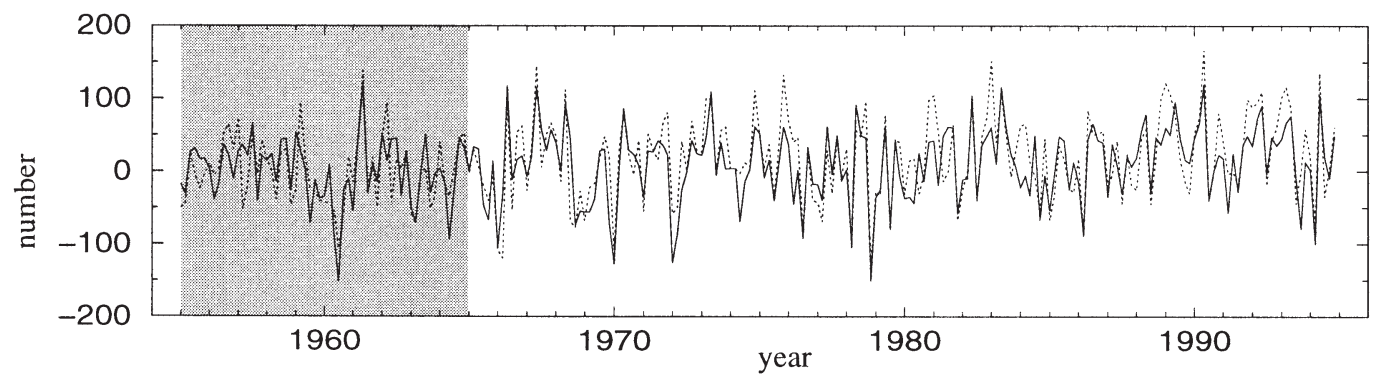

Fig. 3. Time series of the intramonthly frequency of eastwardly propagating waves in the center of the North Sea (in $3 \mathrm{~h}$ time steps, anomalies), as derived from the 'observed' (solid line) and estimated (dotted line) monthly mean air pressure field. The fitting period is shaded 
amounts to 0.58 ( $\times$ standard deviation) in $40 \mathrm{yr}$, whereas the trend for meridionally propagating waves is relatively small. Additionally, the frequency of eastward propagating waves rises markedly (trend $=0.53 \times$ standard deviation), while the occurrence of westward propagating waves becomes less frequent. Between 1955 and 1994 the monthly average time of eastward waves was around $22.5 \mathrm{~d}$ and had a positive trend of $3.5 \mathrm{~d}$ in this period (i.e., in 1955 the expected number of days with eastward propagating waves was about $20.8 \mathrm{~d}$, and in 1994 it was $24.2 \mathrm{~d}$ ).

Because of the noticeable trend in zonal direction, for the rest of the study we focus on the intramonthly frequencies of eastward propagating waves in the winter half year. The apparent decadal trend of the wave direction may be due to long-period natural variability or due to anthropogenically induced changes. To examine this, we used our statistical downscaling model and the available SLP for the 20th century to reconstruct past frequency distributions of the intramonthly wave propagation direction. To do so, the 573 monthly mean SLP fields over the North Atlantic and Western Europe from the winter half years in the period from 1900 to 1996 were used to estimate the intramonthly frequencies of eastward propagating waves at Ekofisk. The $30 \mathrm{yr}$ low-pass-filtered reconstruction is shown in Fig. 4 (solid line).

\section{APPLICATION TO THE GLOBAL CLIMATE CHANGE SCENARIO}

To estimate the future development of our probability of intramonthly wave direction, we used a GCM climate change experiment. As always in downscaling exercises, a crucial assumption is that the statistical relationship between the predictor (SLP) and the predictand (frequency of wave propagation) remains valid in a climate changed because of increased atmospheric greenhouse-gas and aerosol concentrations. The validity of this assumption has been shown to be plausible in a number of studies (Busuioc et al. 1999, Charles et al. 1999, Gonzales-Ruoco, et al. 2000). With the independent wave data from the DNMI wave simulation using the high-resolution time-slice 'control' and ' $2 \times \mathrm{CO}_{2}$ ' simulations, we were able to validate the stability of the statistical link. Fig. 5 shows that the first pattern pairs of the downscaling model do not change under climate change and are comparable to the 'observed' link (notice the $6 \mathrm{~h}$ time step for the scenarios and the $3 \mathrm{~h}$ time step for the 'observed' data). Equal results were obtained for the second pattern pairs (not shown).

The ECHAM4/T106 time-slice experiments provide a $30 \mathrm{yr}$ control run with present day conditions and a 30 yr $2 \times \mathrm{CO}_{2}$ run, simulating a climatic state in equilibrium with doubled atmospheric $\mathrm{CO}_{2}$ concentration and with sea surface temperatures and sea ice distributions at the expected time of doubled atmospheric $\mathrm{CO}_{2}$ concentration (a similar albeit shorter simulation is described by Beersma et al. 1997). The mean change over time of the SLP fields simulated in the 2 time-slice experiments was fed into the downscaling model and resulted in an increase in the frequency of eastwardly propagating waves of around $1.5 \mathrm{~d}$ (i.e. $12.5 \times 3 \mathrm{~h}$ time steps) per month (star in Fig. 4). Such an increase is 3 times the calculated standard deviation in the reconstruction of the past century $\left( \pm 0.5 \mathrm{~d} \mathrm{mo}^{-1}\right.$, see Section $6)$. The second experiment is a transient $240 \mathrm{yr}$ simulation (1860-2099) using a coupled atmosphere-ocean GCM and a horizontal resolution of approximately $2.8^{\circ}$ $\times 2.8^{\circ}$ (T42) for the atmospheric component. The continuously altering SLP field changes were used as predictors in the statistical downscaling model. The dotted line in Fig. 4 shows the smoothed evolution of the estimated wave statistics under continuously changing greenhouse-gas and aerosol concentrations. This evo-

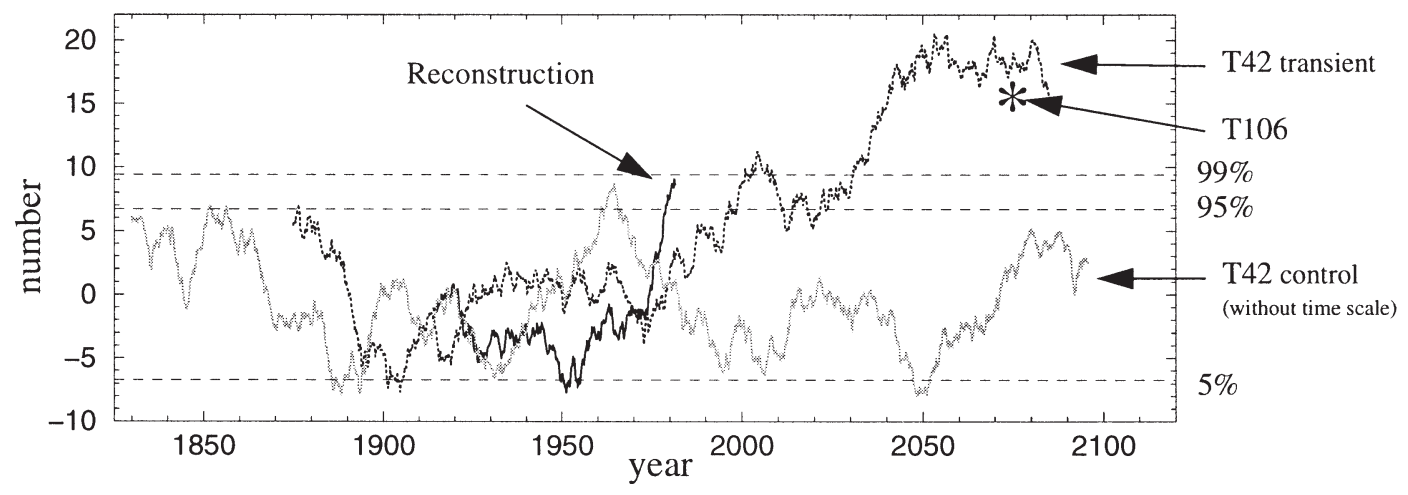

Fig. 4. Comparison of the $30 \mathrm{yr}$ running mean of the monthly frequency of eastwardly propagating waves ( $3 \mathrm{~h}$ time steps, anomalies). The reconstruction of the 20th century (black line), the transient T42 run (dotted line), the T42 control run (grey line) and the time-slice experiment T106 (star) are shown. Dashed lines are the estimated 5, 95 and 99\% confidence intervals 

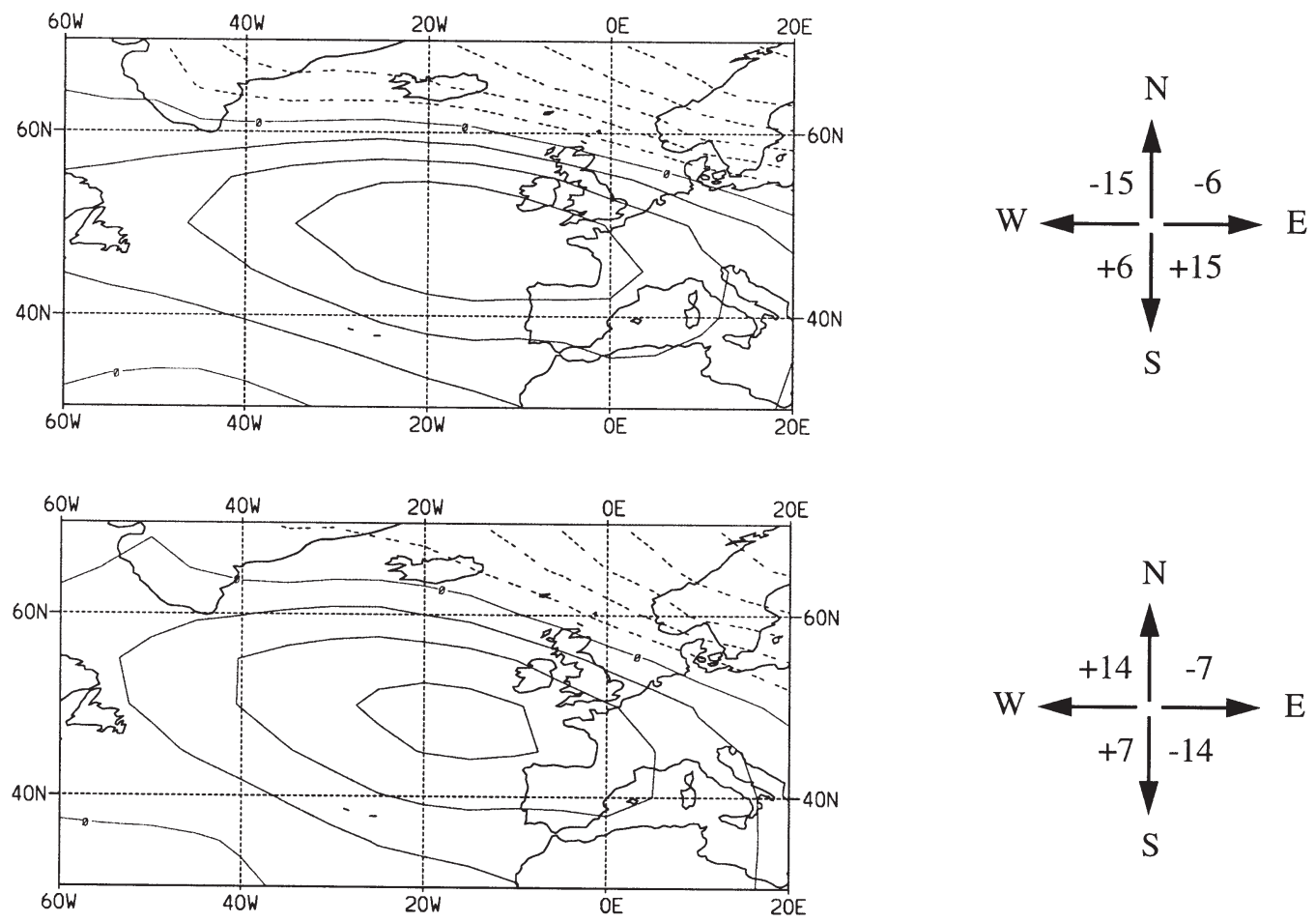

Fig. 5. First pairs of redundancy patterns of winter (ONDJFM) SLP (hPa) in the North Atlantic sector (left) and the 6-hourly frequency of monthly wave direction (right) derived from the time-slice experiment T106. Top (control run): correlation between the time coefficients is 0.85 . Pattern for the wave frequency explains $56 \%$ of the variance. Bottom $\left(2 \times \mathrm{CO}_{2} \mathrm{run}\right)$ : correlation between the time coefficients is 0.79 . Pattern for the wave frequency explains $56 \%$ of the variance

lution is characterized by an ongoing increase in the frequency of eastwardly propagating waves, upon which low-frequency variations are overlaid. To estimate the internal variability in the wave statistics the grey line shows the result from the control run over $300 \mathrm{yr}$ with a constant 1990 greenhouse-gas concentration.

\section{DETECTION OF ANTHROPOGENIC CLIMATE CHANGE}

The first step in the detection strategy is to choose a filter for our wave data that suppresses natural climate variability and leaves the climate change signal intact. The filter chosen here was simply a 30 yr low-pass filter and was a compromise between an emphasis on the relevant climate change signal and a reduction of the interdecadal natural variability.

The next step is to test the null hypothesis that the observed recent change is within the range of variations to be expected in present climate conditions. The null hypothesis will be rejected if the change is larger than $95 \%$ of all cases to be expected in present climate conditions.

The analysed wave statistics from 1955-94 provide too short a record to estimate the range of natural vari- ations in the present climate. In addition this record may be seriously affected by climate change and cannot be directly compared with the outcome of the downscaling model, which systematically underestimates the variability, as all regression models do (von Storch 1999). Therefore we considered only the outcome of estimates derived with the downscaling model, i.e., the data displayed in Fig. 4.

From the observed record, we had only 96 winter half years of reconstructed data. Consequently we had 3 independent $30 \mathrm{yr}$ averages and were not able to specify the distribution; 3 values is too few to estimate a probability distribution for $30 \mathrm{yr}$ changes.

To solve this problem, 2 strategies may be pursued: First, multi-century control simulations may be used as additional data (Hegerl \& von Storch 1996, Stott \& Tett 1998). Here we used the $300 \mathrm{yr}$ control run with present-day (1990) greenhouse-gas concentrations (Fig. 4, grey line). These 3 centuries were still to short to calculate confidence intervals (see above).

The second option is to use a Monte Carlo simulation. Following Hegerl et al. (1996), we constructed an autoregressive first-order process [AR(1)] with normal distribution approximating the time series. We used data from the whole 20th century to fit the AR(1) process, so that our estimate of the variability was also 
influenced by the expected climate change signal. Thus our significance levels are possibly overestimated (test becomes conservative). However, when using only the early part (smaller increase in greenhouse gases) of our reconstruction, the significance levels change only marginally.

Therefore we used a random AR(1) time series for which the autocorrelation coefficient was computed from the reconstructed time series of the intramonthly frequencies of zonal wave propagation. Time series of several $10000 \mathrm{yr}$ length were generated to obtain a robust result for the statistical distribution of $30 \mathrm{yr}$ changes under present-day climatic conditions. This method is able to produce decadal variability (not shown) compared with the control run (Fig. 4, grey line). The resulting significance levels are shown in Fig. 4 (dashed lines), with upper levels labelled 95 and $99 \%$ and a lower level labelled $5 \%$. In the last few years, the analysed increase in the occurrence of eastward propagating waves is beyond the critical $95 \%$ level; thus we may reject the null hypothesis of 'variations within the normal range'. However the possibility of 'non normal' variations must be considered.

The final step of the analysis is to determine whether we can attribute our observed significant climate change to anthropogenic forcing. This cannot be determined in a statistically rigorous manner. However, the identified change can be compared with what the climate change scenarios tell us about the expected change. If these 2 changes, the observed and the expected, are consistent, then we may argue that the cause of the change in the observed record is the same as in the simulation.

To accomplish this comparison, the expected changes, as given by both climate change scenarios (T106 time-slice experiment and T42 transient and control runs), are displayed in Fig. 4. Obviously, the observed changes under climate change conditions are qualitatively similar to the recent past and are dissimilar to the variation in the control run. We conclude that the recent changes in the wave statistics in the central North Sea are consistent with a greenhouse warming signal. We have to take into consideration that these conclusions are based on the ECHAM4 GCM and that the regional prediction still depends on the global model. As Zorita \& Gonzales-Rouco (2000) demonstrated, regional climate change is dependent on the model and the initial conditions of the simulations.

\section{CONCLUSION}

In this paper we have examined the evolution of monthly wave statistics in the central North Sea in the winter half year. Rather than the commonly used variables such as the mean significant wave height and extreme values, we decided to investigate the frequency of intramonthly wave direction. It was found that in recent decades (1955-94) the monthly average time of eastward waves is around $22.5 \mathrm{~d}$, with a positive trend of $3.5 \mathrm{~d}$ during this period. Equal but less steep trends were found for the significant wave height and extreme values.

To assess whether this change is within the range of normal variations, a period of 4 decades is too short. To obtain a longer period, we used a statistical downscaling model to reconstruct the local wave climate for the 20th century. As a predictor we used the observed monthly SLP over the North Atlantic and Western Europe (1900-96), the large-scale circulation patterns of which are affected by regional climate change.

Comparison with the reconstruction of the 20th century and a $300 \mathrm{yr}$ control run indicates that the latest reconstructed $30 \mathrm{yr}$ mean frequency of eastwardly propagating waves is inconsistent with the hypothesis of purely natural variability. Note, however, that rejecting a null hypothesis is not rigorous proof that it is invalid but merely that the evidence supporting it is considered insufficient.

To test whether this significant local climate change can be attributed to an anthropogenic cause, we compared the reconstruction with the results of GCMs (ECHAM4) run with increased greenhouse-gas concentrations and aerosols. A $240 \mathrm{yr}$ transient run and 1 high-resolution time-slice experiment were used as input for our statistical model. The enhanced greenhouse effect in the transient GCM run produced the same qualitative characteristics as those found in the last few decades of our local wave climate, with an upward trend of eastwardly propagating waves. The change in the time-slice experiment was similar and was also outside of the estimated natural variability. This suggests that the wave climate in the North Sea is changing; this might be partly due to global warming, with the restriction that the regional prediction may be dependent on the global climate model.

Acknowledgements. We thank the Max-Planck-Institut Hamburg for providing the ECHAM4/T42 scenario, the Danish Meteorological Institute for the ECHAM4/T106 scenario and the Norwegian Meteorological Institute for the wave data. This research was supported by the 'Environment and Climate Programme' in the project 'STOWASUS 2100' under contract number ENV4-CT97-0498. We thank D. Bray, M. Widmann and Eduardo Zorita for helpful comments.

\section{LITERATURE CITED}

Bauer E, Scrum C, Duwe K (2000) Klimatologie and Prognose klimainduzierte Änderungen hydrographischer Größen in Nord- und Ostsee. BMBF-Projekt KLINO 03F0185A, Abschlussbericht Teilprojekt A, Hamburg, April 2000, p 26 
Beersma J, Rider K, Komen G, Kaas E, Kharin V (1997) An analysis of extratropical storms in the North Atlantic region as simulated in a control and a $2 \times \mathrm{CO}_{2}$ time-slice experiment with a high resolution atmospheric model. Tellus 49A:347-361

Busuioc A, von Storch H, Schnur R (1999) Verification of GCM generated regional precipitation and of statistical downscaling estimates. J Clim 12:258-272

Charles SP, Bates BC, Whetton PH, Hughes JP (1999) Validation of downscaling models for changed climate conditions: case study of southwestern Australia. Clim Res 12: $1-14$

Fyfe JC, Boer GJ, Flato GM (1999) The Arctic and Antarctic Oscillation and their projected changes under global warming. Geophys Res Lett 26:1601-1604

Gonzalez-Rouco F, Zorita E, Heyen H, Valero F (2000) Agreement between observed rainfall trends and climate change simulations in the Southwest of Europe. J Clim 13:3057-3065

Grevemeyer I, Herbert R, Essen HH (2000) Microseismological eveidence for a changing wave climate in the northast Atlantic Ocean. Nature 408:349-352

Günther H, Rosental W, Stawarz M, Carretero JC, Gomez M, Lozano I, Serrano O, Reistad M (1998) The wave climate of the Northeast Atlantic over the period 1955-94: the WASA wave hindcast. Global Atmos Ocean Syst 6: 121-163

Hegerl GC, von Storch H (1996) Applying coupled oceanatmosphere models for prediction, detecting and specifying climate change. Z Angew Math Mech 76 (Suppl 4, I-XII):482-485

Hegerl GC, von Storch H, Hasselmann K, Santer BD, Cubasch U, Jones PD (1996) Detecting greenhouse-gas-induced climate change with an optimal fingerprint method. J Clim 9: $2281-2306$

Hurrell JW (1995) Decadel trends in the North Atlantic Oscillation: regional temperatures and precipitation. Science 269:676-679

IPCC (Intergovernmental Panel on Climate Change) (1996) Climate Change 1995: The science of climate change: Contribution of the Working Group I to the second Assessment Report of the Intergovernmental Panel on Climate Change. Houghton JT, Madeira Filho LG, Callander BA, Harris N, Kattenberg A, Maskell K (eds) Cambridge University Press, Cambridge

Kevin ET, Paolino DA Jr (1980) The Northern Hemisphere sea-level pressure data set: trends, errors and discontinuities. Mon Weather Rev 108(7):855-872

Komen GJ, Cavaleri L, Donelan M, Hasselmann K, Hasselmann S, Janssen PAEM (1994) Dynamics and modelling of ocean waves. Cambridge University Press, Cambridge

Kushnir Y, Cardone VJ, Greenwood JG, Cane MA (1997) The recent increase in North Atlantic wave heights. J Clim 10: $2107-2113$

Langenberg H, Pfizenmayer A, von Storch H, Sündermann J (1999) Storm related sea level variations along the North Sea coast: natural variability and anthropogenic change. Cont Shelf Res 19:821-842

Leroy SS (1999) Optimal detection of global warming using temperature profiles: a methodology. J Clim 12:1185-1198

Editorial responsibility: Chris de Freitas,

Auckland, New Zealand
Livezey RE (1995) The evolution of forecasts. in: von Storch H, Navarra A (eds) Analysis of climate variability: application of statistical techniques. Springer-Verlag, Berlin, p $177-196$

May W (1999) A time-slice experiment with the ECHAM4 A-GCM at high resolution: the experimental design and the assessment of climate change as compared to a greenhouse gas experiment with ECHAM4/OPYC at low resolution. DMI Scientific Report, No. 99-2

Mitchell B, Daley R (1995) Climate response to increase levels of greenhouse gases and sulfate aerosols. Nature 376: 501-504

Roeckner E, Bengtsson L, Feichter J, Lelieveld J, Rohde H (1998) Transient climate change simulations with a coupled atmosphere-ocean GCM including the tropospheric sulphur cycle. Report No. 266. Max-Planck-Institut für Meteorologie, Hamburg

Shindell DT, Miller RL, Smith GA, Pandolfo L (1999) Simulation of the Arctic Oscillation trend by greenhouse forcing of a stratospheric model. Nature 399:453-455

Stott PA, Tett SFB (1998) Scale-dependent detection of climate change. J Clim 11:3282-3294

Tyler DE (1982) On the optimality of the simultaneous redundancy transformations. Psychometrika 47:77-86

von Storch H (1995) Inconsistencies at the interface of climate impact studies and global climate research. Meteorol Z NF $4: 72-80$

von Storch H (1999) On the use of 'inflation' in downscaling. J Clim 12:3505-3506

von Storch H, Zwiers FW (1999) Statistical analysis in climate research. Cambridge University Press, Cambridge

WASA Group (1998) Changing waves and storms in the North Atlantic? Bull Am Meteorol Soc 79:741-760

Wigley TML, Smith RL, Santer BD (1998) Anthropogenic influence on the autocorrelation structure of hemisphericmean temperatures. Science 27:1676-1679

Wilby RL, Wigley TML (1997) Downscaling general circulation model output: a review of methods and limitations. Prog Phys Geogr 21:530-548

Wilby RL, Wigley TML, Conway D, Jones PD, Hewitson BC, Main J, Wilks DS (1998) Statistical downscaling of general circulation model output: a comparison of methods. Water Resour Res 34:2995-3008

Williams J, van Loon H (1976) An examination of the Northern Hemisphere sea-level pressure data set. Mon Weather Rev 104(11):1354-1361

Zorita E, Gonzalez-Rouco F (2000) Disagreement between predictions of the future behavior of the Arctic Oscillation as simulated in two different climate models: implications for global warming. Geophys Res Lett 27(12):1755-1758

Zorita E, von Storch H (1999) The analog method as a simple statistical downscaling technique: comparison with more complicated methods. J Clim 12:2474-2489

Zorita E, Kharin V, von Storch H (1992) The atmospheric circulation and sea surface temperature in the North Atlantic in winter. their interaction and relevance for Iberian rainfall. J Clim 5:1097-1108

Zwiers FW (1999) The detection of climate change. In: von Storch H, Flöser G (eds) Anthropogenic climate change. Springer-Verlag, Heidelberg, p 163-209

Submitted: May 8, 2000; Accepted: February 13, 2001

Proofs received from author(s): July 19, 2001 